\title{
Medievalista
}

Online

$28 \mid 2020$

Número 28

análise e objecções

\section{O realismo direto na teoria da cognição intelectual de Tomás de Aquino}

análise e objecções

Direct realism in Tomás de Aquino's theory of intellectual cognition: analysis and objections

\section{Gilson Damasceno Linhares}

\section{(2) OpenEdition}

\section{Journals}

Edição electrónica

URL: http://journals.openedition.org/medievalista/3341

DOI: $10.4000 /$ medievalista.3341

ISSN: 1646-740X

\section{Editora}

Instituto de Estudos Medievais - FCSH-UNL

\section{Edição impressa}

Paginação: 311-334

\section{Refêrencia eletrónica}

Gilson Damasceno Linhares, «O realismo direto na teoria da cognição intelectual de Tomás de Aquino», Medievalista [Online], 28 | 2020, posto online no dia 01 julho 2020, consultado o 24 março 2021. URL: http://journals.openedition.org/medievalista/3341 ; DOI: https://doi.org/10.4000/ medievalista.3341

\section{Este documento foi criado de forma automática no dia 24 março 2021.}

Mediavalista está licenciado com uma Licença Creative Commons - Atribuição-NãoComercial 4.0 Internacional. 
análise e objecções

\title{
O realismo direto na teoria da cognição intelectual de Tomás de Aquino
}

\author{
análise e objecções \\ Direct realism in Tomás de Aquino's theory of intellectual cognition: analysis \\ and objections
}

Gilson Damasceno Linhares

1 O conceito é o produto do ato intelectivo, mas o que se encontra em nosso intelecto é a mesma forma da coisa ou uma representação da essência desta? Neste contexto surgem duas interpretações possíveis que aparecem no século XX, a saber, o realismo direto e o representacionalismo. Tais interpretações divergem a respeito da relação que o conceito tem com o objeto externo, na teoria do conhecimento, elaborada por Tomás de Aquino ao longo de suas obras. O foco do presente texto será apresentar apenas a interpretação do realismo direto e veremos algumas possiveis objeções.

2 Começaremos apresentando a intepretação do realismo direto a respeito da relação entre conceito e objeto em Tomás, de acordo com as três teses argumentativas principais. Os realistas, pelo fato de defenderem uma cognição direta da coisa, reclamam para si a afirmação de que o objeto imediato de conhecimento do nosso intelecto são as coisas do mundo exterior. O principal motivo pelo qual os realistas negam o representacionalismo, pelo menos do modo como eles o apresentam, é que se o conceito é uma entidade representacional, ela passa a ser necessariamente o nosso objeto imediato de conhecimento. Para conhecer o objeto externo, primeiro precisaríamos direcionar a nossa atenção para o conceito e só depois conhecer o mundo exterior. Por isto deve-se negar o representacionalismo.

3 A segunda tese que iremos expor é que o termo "semelhança" ou "similitude" em outras traduções deve ser entendido no sentido de que há uma identidade formal entre a forma da coisa e o conteúdo formal do conceito. A terceira tese é a noção de 
intencionalidade. Esta é a maneira como Kenny procura explicar o duplo modo de existência das formas na filosofia do aquinate. Um é o modo natural ${ }^{1}$, tal como se encontra no mundo, unida à matéria. $O$ segundo modo é intencional ${ }^{2}$, tal como existe no intelecto, sem matéria. Esta tese procura defender que, apesar da forma existir na realidade de uma maneira e no intelecto de outra, não há falsidade no conhecimento de tal forma, pois há a preservação dos aspectos essenciais destas.

\section{Intelecção direta e o objeto imediato do conhecimento humano.}

4 O realismo direto se caracteriza pela afirmação de que nosso conhecimento intelectual a respeito da coisa material é direto. Por isso, o nosso intelecto tem como objeto imediato de conhecimento as coisas do mundo exterior. A partir daí se pode afirmar que é a coisa material que se encontra em nosso intelecto. Claro que se encontra presente neste ao modo do intelecto, sem matéria.

5 Portanto, no realismo direto nega-se uma entidade mental que garanta o acesso ao objeto material. Isto é, não há representações intermediárias entre o sujeito e a coisa conhecida. Ou pelo menos, não há intermediários que sejam necessários para que possamos conhecer a coisa externa. Então, basta para os realistas admitirem apenas dois elementos no ato cognitivo humano, o sujeito cognoscente e a coisa material.

Entretanto, segundo Stump é importante evitar uma leitura tão rigorosa, quando olharmos o realismo direto, como uma interpretação que diz que temos uma cognição direta das coisas. Pois, quando dizemos cognição direta, compreende-se que a nossa apreensão de um objeto ocorre através de um ato indivisível, isto é, sem que haja a necessidade de que algo cause a nossa percepção desta coisa. Não haveria também a necessidade de nenhum processo intermediário entre o conhecedor e a coisa conhecida. Segundo Stump, isto nos levaria a um realismo ingênuo, pois conhecer deste modo compete apenas a Deus³.

7 Devemos compreender a cognição $0^{4}$ direta como uma apreensão que tem como objeto de conhecimento a coisa externa e não uma species interna. Tal species é apenas a semelhança, efeito da afecção causada em nós pela coisa, e pela qual nós conhecemos o objeto externo. A species aparece como a presença, em nós, da coisa que se encontra no mundo externo. Assim como sei o que acontece em uma partida de futebol, mesmo não estando no estádio, quando a assistimos pela televisão. O que acontece na TV é a transmissão do que ocorre no estádio, porque a TV transmite os dados captados do que está acontecendo no estádio. De fato, há diversas passagens onde Tomás procura reforçar ${ }^{5}$ que as species são o modo pelo qual conhecemos o mundo externo.

Portanto, podemos distinguir duas versões do realismo direto segundo o que foi dito. A primeira versão é chamada de realismo ingênuo, onde não admitiria nenhum processo intermediário entre o sujeito e o objeto. A segunda versão seria um realismo direto modificado, pois admite que há um processo intermediário, contudo, este intermediário não impediria um conhecimento direto. Isto se tornaria possível apenas se admitissemos que esse intermediário, species intelligibilis, possui uma relação de identidade formal para com a forma presente na coisa material.

9 Feita a ressalva para evitar uma leitura ingênua do realismo direto em Tomás, iremos focar na segunda versão do realismo. Vejamos como se apresenta o primeiro argumento 
que caracteriza o realismo direto, que é como o objeto imediato do nosso intelecto são as coisas do mundo externo.

Precisamos deixar claro neste tópico da interpretação representacionalista que sempre que nos referirmos a esta intepretação, falaremos dela sob a ótica dos realistas diretos. Os realistas ${ }^{6}$ parecem se concentrar em um representacionalismo inferencial ou idealista, como chama Pasnau. Este representacionalismo é claramente rejeitado por Tomás em diversas passagens, como veremos no decorrer do texto. Tal leitura tem como característica central a afirmação de que objeto imediato do nosso conhecimento é o conceito e apenas secundariamente e indiretamente conheceríamos a coisa externa.

Dois argumentos ganham destaque, contra a tese de que os conceitos são o objeto de nossa cognição. 0 primeiro é de que seriam impossíveis as ciências naturais, tais como a física, pois esta tem como objeto as coisas que existem fora do intelecto ${ }^{7}$. Se o objeto da nossa cognição fosse o conceito, não conheceríamos os corpos externos e isso impossibilitaria a produção de ciências como a física.

12 O segundo é de que o relativismo seria inevitável. Isso ocorreria pelo fato de que nossos julgamentos se dão sempre sobre aquilo que apreendemos individualmente. Cada indivíduo formaria para si um conceito com base em sua percepção individual e o tomaria como verdadeiro. Isto faria com que todos os nossos julgamentos fossem verdadeiros, mesmo que eles se contradissessem entre si. Com base nesses dois argumentos, Perler se apoia para afirmar que Tomás defende um realismo direto, onde os objetos do nosso intelecto são as formas das coisas do mundo exterior. Portanto, podemos acessá-las diretamente, garantindo assim a objetividade do nosso conhecimento.

13 Para afirmar que a coisa material é o objeto imediato da nossa cognição, por que nossa cognição é direta, os realistas se apoiam em algumas teses para fundamentar sua interpretação da epistemologia tomasiana. A cognição só é dita direta, porque estas teses são pressupostas. A primeira que veremos a seguir é como o termo similitude costuma ser interpretado pelos realistas. $O$ segundo argumento é o da identidade formal, esta prega a igualdade entre o intelecto e a coisa pensada ${ }^{8}$. Aliada a esta, está a tese ontológica da dupla existência da forma, que existe de um modo no intelecto e de outro na coisa. Só é possível admitir a tese da identidade formal, se admitirmos que a mesma forma esteja presente no sujeito e na coisa. Estas teses serão objeto de investigação das próximas seções. Outra tese é que o acesso direto do intelecto à coisa, ocorre porque há uma relação de intencionalidade ${ }^{9}$ entre o ato intelectual e a coisa externa. A intencionalidade nos permitiria prescindir de intermediários cognitivos. Assim, a cognição das coisas materiais é direta e imediata. Não caberia a acusação de um realismo ingênuo, pois a coisa causa sobre nós uma afecção e é recebida como species, isto é, ao modo do sujeito. Contudo, tais species possuem um mero papel instrumental, como veremos. As species possuem um papel fundamental no processo de atualização do intelecto, tornando possível a intelecção, mas não é o alvo de nosso conhecimento. Tornam-se objeto de conhecimento apenas secundariamente. Porém, agora a coisa material já não é mais o alvo do conhecimento. 


\section{Interpretação do Realismo Direto sobre o termo similitude em Tomás de Aquino.}

14 O termo "similitude" é a palavra-chave sobre a qual há uma divergência interpretativa entre os realistas diretos e os representacionalistas. Como visto anteriormente, a species é uma forma intencional, isto é, é o modo como a forma da coisa se torna presente em nossa faculdade cognitiva. Tal species é descrita como uma similitude da forma presente na coisa.

Portanto, o termo "similitude"10 aparece nesta discussão com dois modos possíveis de interpretação. De um lado, o realismo direto interpreta a similitude ou semelhança como uma identidade formal entre as species e a coisa externa. 0 representacionalismo compreende a species como uma representação mental da forma presente na coisa. A escolha de um dos modos de interpretar obviamente nos conduz a uma compreensão radicalmente distinta da epistemologia tomasiana.

Os realistas negam que o termo similitude traga a conotação de representação. Além disso, há muito mais passagens que afirmam a relação de identidade entre o objeto e a nossa faculdade cognitiva ${ }^{11}$.

17 Segundo os realistas, o termo similitude deve ser visto à luz geral do processo de conhecimento humano. Isto significa dizer que o conhecimento ocorre mediante uma identidade formal, pois a cognição acontece sempre quando a forma da coisa está presente no sujeito. A forma se encontra presente no sujeito de modo composto. Todavia, a forma do sensível se encontra no sujeito ao modo de species sensibilis. A forma inteligível se encontra no intelecto ao modo de species intelligibilis.

Em seu artigo, D. Perler apresenta o motivo pelo qual devemos negar o representacionalismo, se a justificativa for apenas as passagens onde o termo similitude sugerisse representação. Por isso, ele defende como, segundo o realismo, deve ser entendida a noção de similitude:

"Dado esse entendimento técnico do termo latino similitudo, seria bastante errôneo atribuir uma posição representacionalista a Tomás de Aquino com base em suas declarações sobre similitude. Pelo contrário, essas afirmações claramente falam a favor de uma versão modificada do realismo direto. Para o que está imediatamente presente ao intelecto quando apreende uma species como semelhança, é a forma de uma coisa - a mesma forma que também é presente na coisa material. É de fato essa relação de identidade, não uma relação de similaridade, que faz uma species uma semelhança. A species funciona como uma semelhança e é, portanto, sobre algo, porque a mesma forma é instanciada em dois lugares diferentes: dentro e fora do intelecto" 12 .

Nesta passagem, Perler indica como o termo similitude é interpretado no realismo direto. A similitude não deve ser interpretada como uma semelhança representacional, isto é, o conceito não é um intermediário entre o sujeito e a coisa. Nem deve ser entendida como imagem da coisa. Antes, deve ser lido com base em duas teses: a noção de identidade formal e de que a forma é algo instanciável. Portanto, similitude deve ser entendida ao modo de identidade formal, assim a species intelligibilis é idêntica à forma da coisa. Só há identidade formal quando similitude é entendida como um compartilhamento de formas. A forma só pode ser compartilhada entre sujeito e coisa quando afirmamos a tese de que a forma é um instanciável. Pois, é a mesma forma que existe no intelecto e fora dele. 

compartilhamento de formas ${ }^{13}$ em seu sentido mais técnico do realismo direto. $\mathrm{Na}$ mesma página do texto Perler distingue três modos de similitude, ou seja, três maneiras como pode ocorrer um compartilhamento de formas.

$\mathrm{O}$ primeiro sentido é quando X e Y compartilham a mesma forma sobre aspecto e modo iguais. Assim como duas coisas compartilham o mesmo grau de brancura. No segundo sentido, X e Y compartilham a mesma forma, segundo o mesmo aspecto, todavia de modos distintos. Duas coisas compartilham a forma da brancura, todavia, em $\mathrm{X}$ a brancura possui grau mais forte do que em Y. No terceiro sentido de similitude, X e Y compartilham a mesma forma, contudo, o aspecto e modo são distintos. Como quando uma coisa quente aquece a outra. A coisa $X$ compartilha a forma da quentura com $Y$, contudo, o faz em graus e aspectos distintos. Pois, X é a causa da quentura de Y. Para Perler, o que é evidenciado com esta distinção entre os sentidos de similitude é o compartilhamento das formas que é comum aos três tipos. Ainda que eles sejam compartilhados de modos e aspectos distintos, não perdem a similitude.

nas quando se admite que a species é a presença da mesma forma da coisa, quando instanciada no sujeito, temos a tese de que a mesma forma é compartilhada entre ambos. A partir daí, poderíamos admitir que nossa faculdade cognitiva tivesse a coisa externa como objeto imediato de cognição.

\subsection{Forma comum e a tese da identidade formal.}

Antes de falarmos sobre a identidade formal, vale ressaltar certo pressuposto que está conectado a tal tese. Vimos no tópico anterior que os realistas reduzem a noção de similitude à identidade formal. o termo similitude aparece com significado técnico de compartilhamento de formas, daí ser possível admitir identidade entre a forma presente no intelecto e na coisa. Neste sentido, a relação de conhecimento entre sujeito e objeto se concretiza quando o sujeito tem presente consigo a mesma forma do objeto. Em outros termos, podemos afirmar que a coisa compartilha a sua forma com o sujeito, já que a coisa é a causa da existência da forma no intelecto humano. Por isso, nesta relação a forma é o que há de comum entre sujeito e objeto. Esta forma comum é o que fundamenta e torna possível a tese da identidade formal do realismo direto. Justamente ela será alvo de breve apresentação, antes de expormos a tese da identidade formal.

\subsubsection{Forma comum}

Para que a mesma forma esteja instanciada em mais de um objeto ou intelecto, devemos admitir que ela possuísse certa universalidade ${ }^{14}$. É justamente a partir daí que Perler afirma que as formas precisam ser universais ${ }^{15}$, apenas assim poderiam estar presentes no intelecto e na coisa ao mesmo tempo. Universal é definido como aquilo que é ou deve ser apto para estar instanciado em diversos.

A forma tomada como universal é essencial para que se possa afirmar a tese da identidade formal. Pois ela nada mais é do que a afirmação de que uma mesma forma existe instanciada na coisa e no intelecto do sujeito de modo conceitual. Se a forma não for, por si, um universal, não poderia encontrar-se nos diversos entes, menos ainda no intelecto. Por consequência, seria impossível conhecermos a coisa, visto que segundo a interpretação realista conhecer é receber a mesma forma da coisa individual. 
26 A epistemologia do realismo direto se caracteriza por dois pontos principais em Tomás, a cognição direta e o processo de assemelhação. Na cognição direta se afirma que não é necessário admitir formas representacionais. Mesmo as species são apenas resultado do processo de assemelhação. Portanto, conhecemos a coisa diretamente. Não é preciso conhecer a species e depois conhecer a coisa. Isto não é necessário simplesmente porque elas não diferem quanto aos dados estruturais (essenciais). Quanto ao processo de assemelhação, no qual as species são o resultado da atividade de recepção da forma da coisa, a forma recebida dos objetos se adequa ao sujeito cognoscente. Por isso, o intelecto recebe a forma inteligível.

Na tentativa de explicar como a mesma forma se encontra no intelecto e fora dele, Perler afirma:

“... há uma segunda tese metafísica à espreita no fundo do realismo direto de Tomás de Aquino. Ele assume que a forma (às vezes também chamada de "natureza") de uma coisa pode ter dois tipos de existência. "Mas essa mesma natureza", afirma, "a chamada natureza humana, tem uma dupla existência: uma material, segundo o modo natural tal como está na matéria, e [outra] imaterial, tal como está no intelecto." O ponto é que é uma e a mesma forma (ou natureza) que pode existir tanto na realidade extramental quanto no intelecto"16.

Para explicar a característica de universalidade desta forma comum entre o intelecto e o objeto, segundo Perler, há uma tese metafísica sustentada por Tomás. Esta consiste na afirmação de que a forma possui duplo modo de existência: material e imaterial ${ }^{17}$. A existência material é o modo natural da forma, que existe unida a matéria. A existência imaterial é o modo como se encontra no intelecto. Devido à possibilidade de uma mesma forma manter sua identidade mesmo neste duplo modo de existência é que podemos afirmar a tese da identidade formal. Pois, é a mesma forma que está instanciada em distintos.

Procuraremos analisar algumas dificuldades desta tese em contraposição com outros pontos da filosofia tomasiana. Isto será feito no tópico dificuldades na interpretação realista.

\subsubsection{Identidade formal}

Esta talvez seja a principal tese do realismo direto: a identidade formal entre a forma da coisa e o conceito presente no intelecto. Para explorar essa tese, veremos as principais passagens tomasianas utilizadas para fundamentá-la. Acompanhada destas passagens veremos os argumentos desta proposta interpretativa.

31 A tese da identidade formal é tão fundamental para a interpretação realista que Norman Kretzmann afirma o seguinte:

"A garantia de que o acesso é totalmente direto, ao ponto de [haver] identidade formal entre o objeto extra mental e a faculdade cognitiva ao conhecer esse objeto..." ${ }^{18}$.

Então a identidade formal é o que garante que o acesso intelectual ao objeto seja totalmente direto. Isto se deve ao fato de que, quando o intelecto está conhecendo o objeto, ambos são formalmente idênticos. A identidade ocorre no ato de conhecer. Tomás de fato afirma algo neste sentido em alguns textos. N. Kretzmann se apoia na seguinte passagem para afirmar isto: "o intelecto em ato e o inteligível em ato são a mesma coisa da mesma maneira que os sentidos em ato e os sensíveis em ato". ${ }^{19} \mathrm{~A}$ concordância entre intelecto e coisa é tal que não basta que a coisa esteja em ato para 
haver identidade entre eles. $O$ intelecto deve estar necessariamente em ato ao mesmo tempo. Apenas quando está em ato, o intelecto está atualmente conhecendo. Para Tomás o ato de conhecer significa ter presente consigo a forma daquilo que se conhece. Todavia, com a afirmação de identidade formal apresentada pelos realistas, podemos inferir que conhecer é ser, em certa medida, a forma que se conhece, visto que a afirmação tomasiana diz que o intelecto enquanto conhece é a mesma coisa que o objeto. A tese de que conhecer é se assemelhar a coisa conhecida pode reforçar ainda mais esta ideia. Conhecer deste modo, com identidade formal, garante certa objetividade da atualização da faculdade cognoscitiva em relação ao seu objeto. Ora, é a mesma coisa que está no objeto que também atualiza o nosso intelecto. Há ainda a garantia de que todos os seres acessam a mesma forma. Assim formamos universalmente o conhecimento.

Além de a forma comum fundamentar a possibilidade de haver identidade formal, é preciso também que esta forma possua outra característica, como vimos que é a universalidade. Só podemos admitir identidade formal porque é a mesma forma que se encontra atualmente presente no intelecto do sujeito e no objeto conhecido. Por isso, vamos falar sobre esta condição postulada pelos realistas da forma estar instanciada de dois modos.

Kenny, ao falar desta dupla instanciabilidade da forma, apresenta resumidamente o que P. Geach diz sobre as ocorrências individuais da forma:

"O que faz uma sensação ou pensamento de um X ser um X é que é uma ocorrência individual dessa mesma forma ou natureza que ocorre em um X - é assim que nossa mente 'alcança a realidade'; o que faz com que seja uma sensação ou pensamento de um X em vez de um X real ou um X (...) é que ocorre aqui da maneira especial chamada esse intencionale, e não da maneira "comum" chamada esse naturale"20.

Segundo Kenny, a forma pode ser instanciada de dois modos: intencional e natural ${ }^{21}$. 0 modo intencional ${ }^{22}$ é a maneira característica de como recebemos a forma do objeto conhecido, sem o acompanhamento da matéria individual. O modo natural é a maneira como a coisa existe, materialmente. Assim, a identidade formal pode ser justificada porque a mesma forma vem a existir de modo duplo. Existe intencionalmente no intelecto e naturalmente no objeto.

Uma questão que surge a esta tese é a de que o objeto seria apreendido de modo distinto da realidade. Isto, por conseguinte, nos levaria a apreender falsamente o objeto externo. Todavia, Kenny diz que não haveria falsidade alguma, na apreensão intencional das coisas. Pois, a forma intencional traz consigo a mesma estrutura essencial que se encontra no objeto externo. A única distinção entre tais formas é o modo como elas estão instanciadas ${ }^{23}$.

37 É possível encontrar algumas passagens nos textos de Tomás que se referem à dupla existência da forma. No comentário ao De Anima o filósofo diz:

"Agora uma natureza - digamos a natureza humana -, que pode ser pensada universalmente, tem dois modos de existência: um, material, na matéria fornecida pela natureza; o outro, imaterial, no intelecto" ${ }^{24}$.

Com base nesta passagem, a tese da recepção intencional da forma, apresentada por Kenny, tem fundamento na filosofia de Tomás, onde a forma existe unida à matéria ${ }^{25}$, na coisa, no caso das substâncias compostas e sem esta, quando recebida no intelecto. Uma questão pode ser levantada. O que torna possível a forma ter a chamada, por 
Kenny, existência intencional? É a noção de intencionalidade que será abordada no tópico seguinte.

\section{Intencionalidade}

Em seu artigo ${ }^{26}$, Kenny procura fazer uma análise sobre a noção de intencionalidade em Tomás. De modo resumido Kenny apresenta a noção de intencionalidade da seguinte maneira:

“Ambos a percepção dos sentidos e a aquisição de informações intelectuais, a recepção de formas de maneira, mais ou menos imaterial, por um ser humano. Tanto na percepção quanto no pensamento, existe uma forma intencional. Quando eu vejo a vermelhidão do sol poente, a vermelhidão existe intencionalmente em minha visão; quando penso na redondeza da terra, a sua forma circular existe no meu intelecto. Em cada caso, a forma existe sem a matéria à qual está associada na realidade: o sol em si não entra nos meus olhos, nem a terra, com toda a sua massa, muda para o meu intelecto" ${ }^{27}$.

Portanto, a intencionalidade trata do modo humano de recepção de dados do mundo externo. A intencionalidade procura explicar como a forma da coisa passa a existir no sujeito que conhece. Este modo de existência se aplica tanto às formas sensíveis, que passam a existir nos sentidos - como visto, o processo de recepção de tais formas conservam as características individuais da coisa -, quanto às formas inteligíveis que existem no intelecto. Esta forma existe no intelecto sem nenhum traço de individualidade, pois é pensada sem matéria individual.

Kenny procura, ainda, distinguir existência intencional de existência imaterial. Para isto, o autor oferece dois exemplos que se referem à existência de algo e à recepção deste algo. Basicamente, a distinção entre a existência intencional e a imaterial é esta. A coisa B pode existir imaterialmente, mas quando pensada, ela é recebida intencionalmente. Sua existência é intencional quando está presente em um sujeito. Kenny oferece dois exemplos, um se refere à recepção de uma forma sensível e outro à de uma inteligível. Na recepção da forma sensível ele oferece o seguinte exemplo: uma coisa existe natural e materialmente em um objeto colorido. Entretanto, quando é recebido no olho, passa a existir intencionalmente. No exemplo da recepção de uma forma inteligível ele diz: o arcanjo Gabriel é uma forma naturalmente imaterial, mas, quando pensado por Rafael, então toma uma existência imaterial e intencional no intelecto do sujeito cognoscente. Para Kenny este é o modo característico do pensamento intelectual humano, a imaterialidade. Pois o intelecto é imaterial, e a intencionalidade, modo como este recebe a forma da coisa externa.

\section{Dificuldades na interpretação realista}

Neste tópico, pretendemos apresentar algumas dificuldades que surgem na admissão das teses realistas. Iniciaremos analisando a tese de identidade formal. Esta é uma suposição metafísica do realismo direto que, como demonstrado em tópicos anteriores, visa tornar possível a objetivação do conhecimento intelectual humano. Esta objetividade se tornaria possível através do estabelecimento de uma forma comum entre o intelecto e a coisa. Após isto, apontaremos a dificuldade na aceitação da tese a 
respeito da forma comum. Pois esta é tomada como um universal que existe na coisa singular. Todavia, Tomás diz que tudo no indivíduo é totalmente individualizado.

Passaremos agora para a análise da dificuldade que a tese da identidade formal nos impõe.

\subsection{Dificuldades na tese da identidade formal}

44 A tese central do realismo direto é a noção de identidade formal. Para ficarem claras as dificuldades que pretendemos apontar, vamos relembrar algumas coisas. Esta tese afirma a identidade entre a forma presente no intelecto e na coisa material. Segundo os realistas, a mesma forma está instanciada em dois lugares distintos. Isto, porque a forma possui um duplo modo de existência intencional no intelecto e natural, quando instanciada na coisa.

45 A tese da identidade formal é defendida pelos realistas com base em passagens onde Tomás sugere coisas como "o intelecto em ato e o inteligível em ato são uma e a mesma coisa, da mesma maneira que o sentido em ato e o sensível em ato". ${ }^{28}$

Duas são as dificuldades que podemos apontar com base nesta passagem. A primeira é a transposição da relação, no âmbito sensível, entre os sentidos e os sensíveis, para a relação, no âmbito inteligível, entre o intelecto e os inteligíveis. A segunda é a identidade entre o intelecto e o inteligível, tese negada por Tomás. Afirmar isto seria um erro ainda pior cometido pelos realistas.

47 Quanto a esta transposição da relação das faculdades cognitivas com seus objetos será analisada. Na faculdade sensível os sentidos são colocados em ato na recepção dos sensíveis. Ora os objetos sensíveis já se encontram em ato. Por isso, eles podem atualizar os nossos sentidos que antes estavam em potência. Esta é a primeira diferença entre as faculdades sensível e inteligível, a passividade inicial na cognição da coisa.

O segundo ponto é que no âmbito sensível não há diferença genérica entre a natureza dos sentidos e dos objetos. Ambos são compostos de matéria. Portanto, há a preservação de todas as características singulares do objeto sensível. Ficando patente a identidade em ato entre os sentidos e sensíveis.

49 Surge um problema quando os realistas tentam igualar este processo que ocorre no âmbito sensível ao ato intelectivo. Pois, o inteligível só existe em ato no intelecto. Sua existência na coisa é apenas potencialmente inteligível. Verificamos nesta relação o oposto do que ocorre entre os sentidos e os sensíveis. Se lá havia igualdade genérica entre a natureza dos sentidos e os respectivos objetos, aqui não há essa igualdade, pois, o intelecto sendo totalmente imaterial só conhece inicialmente os universais. Todavia, a forma sobre a qual ele abstrai está unida à matéria. Sendo, portanto, uma forma individual.

50 Então para haver identidade formal entre conceito e objeto é preciso enfrentar duas teses: 1.0 inteligível em ato só existe no intelecto, como resultante da abstração; 2. A coisa é inteligível apenas potencialmente, pois está unida à matéria.

51 A segunda dificuldade da passagem e que seria um erro absurdo dos realistas é a afirmação da identidade entre o intelecto e o inteligível em ato. Aqui já não é a relação entre o inteligível potencial, tal como existe na coisa, e o intelecto. Entretanto, o inteligível em ato no intelecto, como resultado da abstração, ao modo de species 
intelligibilis, que se tornará conceito, como produto final do ato intelectivo. Ambos não podem ser igualados, como o próprio Tomás afirma:

"Ademais, que a intenção inteligida em nós não se identifica com o intelecto, depreende-se do fato de que o ser da intenção inteligida consiste na própria

intelecção; não, porém, o ser do nosso intelecto, pois este ser não se identifica" ${ }^{29}$.

Esta passagem deixa claro que Tomás distingue o inteligível, o conceito ${ }^{30}$, e o intelecto. Podemos afirmar a identidade entre o inteligível e o ato do intelecto, mas este também é distinto do intelecto. Tomás afirma em outras passagens que apenas em Deus o ato e o ser se identificam. Pois, Deus é ato puro. Nosso intelecto, por outro lado, precisa ser atualizado na recepção do universal. Enquanto isso está em potência para seu objeto de conhecimento.

Para falarmos de identidade formal no realismo direto, precisamos ter claro que esta relação não é entre intelecto e inteligível. Todavia, é uma relação entre o conteúdo formal do conceito atualmente no intelecto e a forma presente na coisa.

Como solução para a identidade entre a forma presente no intelecto, ao modo de conceito, e a que atualiza a coisa, os realistas propõem a tese da dupla existência da mesma forma, a saber, intencional e natural. Esta tese pode ser encontrada textualmente em Tomás. A partir disto surge o termo forma comum: a forma que é compartilhada entre intelecto e a coisa, no ato do conhecimento. Tal tese da forma comum enquanto universal existente na coisa será nosso objeto de análise a seguir.

\subsection{Dificuldade na tese da forma comum}

A noção de forma comum ${ }^{31}$ exige dois elementos fundamentais. O primeiro é a composição hilemórfica das coisas materiais. Estas são as substâncias compostas de forma e matéria, onde os dois princípios, formal e material, constituem a essência da coisa. O segundo elemento fundamental é a tese da dupla existência da mesma forma. Vimos que a mesma forma pode existir de dois modos. Uma é a existência imaterial, segundo está disposta no intelecto, outra é a existência material, tal como está disposta na coisa, unida à matéria.

56 A dificuldade que apontaremos se concentrará na segunda tese, a saber, a dupla existência da forma. Ora, a forma comum que existe de modo duplo, no intelecto e na coisa material, como afirmado anteriormente, é universal. No primeiro modo de existência afirmado, no intelecto, existe sem matéria. Portanto, não há nenhuma contradição. Visto que a forma é universal e está no intelecto sem a matéria. Todavia, a tese do realismo direto afirma que é a mesma forma que está instanciada no intelecto e no sujeito. Isto nos leva a afirmar que a mesma forma universal ${ }^{32}$ que se encontra no intelecto está presente na coisa material.

57 O problema que surge com esta suposição da coisa ser composta por forma universal e matéria determinada é uma tese metafísica tomasiana. Em tal tese Tomás afirma que tudo no indivíduo é totalmente individualizado ${ }^{33}$. Então a forma presente no sujeito não pode ser universal.

Além disso, admitir a tese da forma comum, entendida como universal presente nas coisas, seria ao mesmo tempo admitir a existência de universais independentes do intelecto. Se houver a admissão da existência de tal forma, independente da cognição intelectual, então seria possível defender a tese da identidade formal. Pois, haveria a 
ocorrência da mesma forma. De um modo a mesma forma seria especificadora da essência da coisa. De outro modo especificaria o conteúdo inteligido.

Parece que, segundo a interpretação realista, a essência da coisa material é composta de uma forma universal e matéria determinada ${ }^{34}$, onde a forma universal ao ser recebida pela matéria determinada se torna algo individual. A forma qualifica a espécie do indivíduo, contudo, não o determina enquanto singular. Tal forma seria a propriedade que pode ser afirmada de muitos, visto que é universal. Todavia, não nos permitiria distinguir as coisas. Entretanto, garantiria a unidade e a identidade formal dos diversos indivíduos.

Todavia, este é o papel da matéria, a individuação da coisa. Nesta visão das substâncias hilemórficas que é a coisa material, o único componente que a tornaria individual é a sua matéria, visto que tal matéria, enquanto princípio de individuação, é a única coisa que não é comum a outros indivíduos. A matéria enquanto propriedade singular nos permitir distinguir os indivíduos entre si. Então tudo que corresponde à parte formal, como o intelecto, por exemplo, seria compartilhado entre os indivíduos da mesma espécie? Seria absurdo admitir isso para Tomás.

61 Portanto, se a parte formal das substâncias materiais for um universal, como os realistas a interpretam, precisaríamos negar a tese metafísica tomasiana de que tudo no indivíduo é totalmente individualizado. Pois, o aspecto formal, enquanto compõe a substância hilemórfica, não é algo individualizado, segundo os realistas.

Com as teses da identidade formal e forma comum, os realistas não conseguem explicar como conhecemos as coisas singulares em Tomás. Visto que a matéria seria o único princípio de individuação, esta, a matéria, não pode ser conhecida diretamente pelo intelecto devido à imaterialidade deste.

\section{BIBLIOGRAFIA}

Fontes (Obras de Tomás de Aquino):

THOMAS AQUINAS in English. Org. Joseph Kenny. Dominican House of Philosophy, 1963. Versão eletrônica disponível em http://www.dhspriory.org/thomas/

TOMÁS DE AQUINO - Comentário ao Tratado da Trindade de Boécio. Trad. Carlos Arthur Ribeiro do Nascimento. São Paulo: Fundação Editora da UNESP, 1998.

TOMÁS DE AQUINO - Corpus Thomisticum. Org. Enrique Alárcon. Panplona: Universidade de Navarra, 200. Versão eletrônica disponível em http://www.corpusthomisticum.org/iopera.html.

TOMÁS DE AQUINO - O ente e a essência. Trad.: Mário Santiago de Carvalho, Covilhão: LusoSofia, 2008.

TOMÁS DE AQUINO - Questões Disputadas sobre a Alma. Trad. Luiz Astroga. São Paulo: Realizações, 2012.

TOMÁS DE AQUINO - Suma contra os gentios. 2 vols. Trad. D. Odilão Moura. Porto Alegre: Sulina, 1990. 
TOMÁS DE AQUINO - Suma teológica. Primeira parte. v. I e II. Trad. Carlos Josaphat. São Paulo: Loyola, 2001.

Estudos:

DAVIES, Brian (ed.) - Thomas Aquinas. Contemporary philosophical perspectives Oxford: Oxford University Press, 2002.

HALDANE, John - “Aquinas on Sense-Perception”. The Philosophical Review 92:2 (1983), pp. 233-239.

HOFFMAN, Paul - "Direct Realism, Intentionality and the Objective Being of Ideas". Pacific Philosophical Quartely 83 (2002), pp. 163-179.

JANUNZI NETO, Antonio - Tomás de Aquino e a viabilidade do Realismo Direto: questões sobre a natura communis. Rio de Janeiro: Universidade Federal do Rio de Janeiro, 2017. Tese de Doutoramento.

KENNY, Anthony - Aquinas: A collection of critical essays. Garden City, N.Y.: Anchor Books, 1969.

KENNY, Anthony - Aquinas on Mind. New York: Routledge, 1994.

KENNY, Anthony - Aquinas on Being. Oxford: Oxford University Press, 2002.

KENNY, Anthony - "Intentionality: Aquinas and Wittgenstein". In DAVIES, Brian (ed.) - Thomas Aquinas. Contemporary Philosophical Perspectives. Oxford: Oxford University Press, 2002, pp. 243-256.

KRETZMANN, Norman - "Infallibility, error, and ignorance". Canadian Journal of Philosophy 21, suppementary volume 27 (1991), pp. 159-194.

KRETZMANN, Norman - "Philosophy of mind". in KRETZMANN, Norman: STUMP, Eleonore (org.) - The Cambridge companion to Aquinas. Cambridge: Cambridge University Press. 1993, pp. 128-159.

KRETZMANN, Norman - The Metaphysics of Creation. Oxford: Oxford Clarendon Press, 2005.

KRETZMANN, Norman; STUMP, Eleonore (org.) - The Cambridge companion to Aquinas. Cambridge: Cambridge University Press, 1993.

LANDIM FILHO, Raúl F. - “Tomás de Aquino: Realista Direto?”. Analytica 15:2 (2011), pp. 13-38.

PASNAU, Robert - The Identity of Knower and Known. Chicago/Illinois: American Philosophical Association Central Division, April 25, 1996. Disponível em https://faculty.fordham.edu/klima/ APAPasnau.htm

PERLER, Dominik - "Essentialism and Direct Realism: Some Late Medieval Perspectives". Topoi 19 (2000), pp. 111-122.

SPRUIT, Leen - Species Intelligibilis: From Perception to Knowlegde. Leiden: Brill, 1994.

STUMP, Eleonore - Aquinas. London: Routledge, 2003.

TORRELL, Jean-Pierre - Iniciação a Santo Tomás de Aquino: segundo sua pessoa e obra. Tradução de Luiz Paulo Rouanet. $2^{\circ}$ ed. São Paulo: Loyola, 1999.

\section{NOTAS}

1. KENNY, Anthony - "Intentionality: Aquinas and Wittgenstein". In Thomas Aquinas. Contemporary Philosophical Perspectives. Ed. B. Davies. Oxford: Oxford University Press, 2002, p. 146.

2. KENNY, Anthony - "Intentionality: Aquinas and Wittgenstein“ ..., p. 146.

3. STUMP, Eleonore - Aquinas. London: Routledge, 2003, p. 245.

4. 0 termo cognição se repetirá muito ao longo do nosso texto. Ele deve ser entendido como o processo de aquisição dos dados intelectuais recebidos. 
5. TOMÁS DE AQUINO - Suma de Teologia I q.85, a.2, ad.2.p. 522

6. Apenas para citar alguns: KRETZMANN, Norman - "Philosophy in Mind". in KRETZMANN, Norman; STUMP, Eleonore (org.) - The Cambridge companion to Aquinas. Cambridge: Cambridge University Press, 1993, pp. 128-159; PERLER, Dominik - "Essencialism and Direct Realism: Some Late Medieval Perspectives". Topoi 19 (2000), pp. 111-122.

7. TOMÁS DE AQUINO - Suma de Teologia I ${ }^{\circ}$ questão 84, artigo 1, p. 509.

8. Norman Kretzmann se apoia na seguinte passagem para afirmar isto: "o intelecto em ato e o inteligível em ato são a mesma coisa da mesma maneira que os sentidos em ato e os sensíveis em ato”. TOMÁS DE AQUINO - Suma Contra os Gentios, livro IV, capítulo II, n59, p. 721.

9. Estamos utilizando o termo intencionalidade aqui apoiados no artigo de Anthony Kenny, onde ele descreve a noção de intencionalidade na filosofia do aquinate como um modo de recepção das formas sensível e inteligível: “Tanto na percepção sensorial quanto na aquisição de informação intelectual, a recepção da forma é feita de uma maneira mais ou menos imaterial, por um ser humano. Em ambos, na percepção e no pensamento, existe uma forma intencional. Quando vejo a vermelhidão do sol poente, a vermelhidão existe intencionalmente na minha visão, quando penso na redondeza da Terra, a circularidade existe no meu intelecto. Em cada caso a forma existe sem a matéria a que se juntou na realidade: o próprio sol não entra no meu olho, nem a Terra, com toda a sua massa, passa para o meu intelecto" (KENNY, Anthony - "Intentionality: Aquinas and Wittgenstein"..., p. 253).

10. Em latim similitudo.

11. As principais passagens mais utilizadas pelos realistas que afirmam uma relação de identidade e que o objeto imediato de cognição é a coisa externa são: TOMÁS DE AQUINO - Suma de Teologia I ${ }^{\circ}$ q.78, a.3 c, p. 402.

12. PERLER, Dominik - “Essentialism and Direct Realism” ..., p. 116.

13. PERLER, Dominik - “Essentialism and Direct Realism” ..., p. 115.

14. Há diversas passagens onde Tomás afirma a existência desta forma comum ou natureza comum. Como se segue: “toda forma recebida em um refratário singular (matéria) pelo qual é individualizada é comum a muitos, seja realmente, seja pelo menos quanto à razão. Por exemplo, a natureza humana é comum a muitos, realmente e quanto à razão" - TOMÁS DE AQUINO - Suma de Teologia I ${ }^{a}$ q.19, a.1 ad.3, p. 262.

15. PERLER, Dominik - "Essentialism and Direct Realism” ..., p. 116.

16. PERLER, Dominik - “Essentialism and Direct Realism” ..., p. 113.

17. TOMÁS DE AQUINO - De Anima II, 12, Leonina XLV/1, 116 (Marietti edition: II, 12, n. 378)

18. KRETZMANN, Norman - "Philosophy of Mind" ..., p. 138.

19. Tomás também afirma algo semelhante em: Suma Contra os Gentios, livro IV, cap. II, n59, p. 721.

20. KENNY, Anthony - "Intentionality: Aquinas and Wittgenstein" ..., p.247.

21. KENNY, Anthony - "Intentionality: Aquinas and Wittgenstein" ..., p. 248.

22. O termo intencional ou intencionalidade será objeto de atenção no próximo tópico, onde explicaremos com mais detalhes como Kenny apresenta a intencionalidade na filosofia tomasiana.

23. Especificamente Norman Kretzmann fala sobre isto em seus dois textos: "Philosophy of mind", cit. e The Metaphysics of Creation. Oxford: Oxford Clarendon Press: 2005.

24. TOMÁS DE AQUINO - De Anima II, 12, Leonina XLV/1, 116 (Marietti edition: II, 12, n. 378): "Ista autem natura, cui advenit intentio universalitatis, puta natura hominis, habet duplex, tal: unum quidem materiale, secundarium quod est in materia naturali; aliud autem imateriale, secundarium quod est in intellectu".

25. Neste caso, a matéria tomada como princípio de individuação. 
26. KENNY, Anthony - "Intentionality: Aquinas and Wittgenstein“ ..., p. 252.

27. KENNY, Anthony - “Intentionality: Aquinas and Wittgenstein” ..., p. 253.

28. TOMÁS DE AQUINO - Suma Contra os Gentios, livro IV, cap. II, nº 59, p. 722.

29. TOMÁS DE AQUINO - Suma Contra os Gentios, livro IV, cap. 11, n.3466, p. 722: “Quod autem intentio intellecta non sit ipse intellectus in nobis, ex hoc patet quod esse intentionis intellectae in ipso intelligi consist: non autem esse intellectus nostri, cuius esse non est suum intelligere."

30. No decorrer desta passagem, Tomás se refere ao conceito como verbo ou intenção inteligida.

31. Isto é, apto a existir em muitos ou algo que é comum a muitos. Daí o nome forma comum ou natureza comum.

32. Estamos utilizando o termo forma comum no mesmo sentido de forma universal.

33. TOMÁS DE AQUINO - Ente e a essência ..., p. 32. Neste trecho específico, Tomás fala sobre o modo de existência da forma universal nas coisas singulares. Mesmo que a forma seja um universal, quando existente nas coisas singulares, ela existe individualizada no indivíduo.

34. O termo matéria determinada é o princípio de individuação.

\section{RESUMOS}

Este texto tem como objetivo uma apresentação introdutória da hipótese interpretativa do realismo direto, no que diz respeito à relação entre o conceito e o objeto, na gnosiologia tomasiana. O realismo direto levanta a hipótese de que há uma relação de identidade formal entre a species intelligibilis/conceito e a coisa externa. Devido a esta tese da identidade formal, devemos negar que tais entidades sejam intermediárias entre o intelecto e a coisa. Portanto, a negação de uma entidade mental intermediária excluiria uma interpretação representacionalista. Pretendemos, após analisar as principais teses do realismo direto, propor algumas objeções a estas. Teremos como foco de objeção a tese central da identidade formal e o fundamento desta, a saber, a forma comum.

This text aims at an introductory presentation of the interpretative hypothesis of direct realism, with regard to the relationship between the concept and the object, in Thomasian gnosiology. Direct realism raises the hypothesis that there is a formal identity relationship between the species intelligibilis / concept and the external thing. Due to this thesis of formal identity, we must deny that such entities are intermediaries between the intellect and the thing. Therefore, the denial of an intermediate mental entity would exclude a representationalist interpretation. After analyzing the main theses of direct realism, we intend to propose some objections to these. We will object to the central thesis of formal identity and its basis, namely, the common form.

\section{ÍNDICE}

Keywords: Thomas Aquinas, Concept, Object, Identity, Intellect, Thing

Palavras-chave: Tomás de Aquino, Conceito, Objeto, Identidade, Intelecto, Coisa 


\section{AUTOR}

\section{GILSON DAMASCENO LINHARES}

Bolsista da FAPESB (Fundação de Amparo a Pesquisa da Bahia) 42738845 Lauro de Freitas, Bahia,

Brasil.linhares753@gmail.com. https://orcid.org/0000-0002-4008-3379 